\title{
Obtenção e caracterização de iogurtes elaborados com leites de ovelha e de vaca ${ }^{1}$
}

\author{
Ligia Maria Revers ${ }^{2}$, Angélica Jacobi Danielli², Sidiane Iltchenco², Jamile Zeni ${ }^{3}$, \\ Clarice Steffens ${ }^{3}$, Juliana Steffens ${ }^{3}$ *
}

$10.1590 / 0034-737 X 201663060001$

\section{RESUMO}

O objetivo deste trabalho foi obter e caracterizar (físico-química, reológica e microbiologicamente) iogurtes elaborados a partir de leite de ovelha (integral e semidesnatado) e de leite de vaca (integral e semidesnatado). Foram realizadas análises físico-químicas ( $\mathrm{pH}$, acidez, proteínas, lactose, gordura, cinzas e minerais) e microbiológicas (Salmonella spp., Staphylococcus coagulase positivas e coliformes a $35^{\circ} \mathrm{C}$ ), nos leites e nos iogurtes e, de sinérese, nos iogurtes, nos $1^{\circ}$, $15^{\circ}$ e $35^{\circ}$ dias de armazenamento. A partir das análises físico-químicas, verificou-se que o leite de ovelha, integral e semidesnatado, é mais rico, nutricionalmente, que o leite de vaca integral e semidesnatado, e que os iogurtes com leite de ovelha, tanto integral como semidesnatado, apresentaram os maiores valores de gordura, proteína, pH, lactose, minerais e maior sinérese que os iogurtes com leite de vaca, integral e semidesnatado.

Palavras-chave: gordura; proteína; acidez; lactose; sinérese.

\section{ABSTRACT}

\section{Acquisition and characterization of yogurts produced with sheep and cow milk}

The objective of this work was to obtain and characterize (physicochemical, rheological, and microbiologically) yogurt made from sheep milk (whole and semi-skimmed) and cow milk (whole and semi-skimmed). Physical and chemical analysis ( $\mathrm{pH}$, acidity, protein, lactose, fat, ash and minerals) and microbiological analysis (Salmonella spp., Staphylococcus coagulase positive and coliforms at $35^{\circ} \mathrm{C}$ ) were carried out in the milk and yogurts and syneresis in yoghurts held on $1 \mathrm{st}, 15^{\text {th }}$, and 30th days of storage. From the physical-chemical analysis, it was found that the fully and semi-skimmed sheep milk is nutritionally richer when compared to whole and semi-skimmed cow milk and yoghurts with both whole and semi-skimmed sheep milk presented the higher values of fat, protein, $\mathrm{pH}$, lactose, minerals, and higher syneresis when compared to the yoghurt with whole and semi-skimmed cow milk.

Key words: fat; protein; acidity; lactose; syneresis.

' Este trabalho é parte do trabalho de conclusão de curso da primeira autora.

${ }^{2}$ Universidade Regional Integrada do Alto Uruguai e das Missões, Erechim, Rio Grande do Sul, Brasil. ligiaea@gmail.com; angelicajdanielli@hotmail.com; sidiane.i@hotmail.com ${ }^{3}$ Universidade Regional Integrada do Alto Uruguai e das Missões, Departamento de Ciências Agrárias, Erechim, Rio Grande do Sul, Brasil. jamilezeni@uricer.edu.br; clarices@uricer.edu.br; julisteffens@uricer.edu.br

*Autora correspondente: julisteffens@uricer.edu.br
} 


\section{INTRODUÇÃO}

Do ponto de vista nutricional, o leite é um dos alimentos mais completos em virtude do elevado valor biológico, da alta digestibilidade e de constituir excelente fonte de proteína e cálcio. Por esses fatores, seu consumo está presente desde os primórdios da civilização humana (Barbosa et al., 2010, Santos, 2011). A diferença da composição do leite entre as espécies é significativa e o leite de ovelha, por exemplo, apresenta maiores teores de proteína, cálcio, fósforo e lipídeos de alta qualidade que o leite de vaca. Além de ser mais nutritivo e de fácil digestão, contém pequenos glóbulos de gordura que proporcionam maior área de contato entre si e as enzimas digestivas, tornando seu aproveitamento mais eficiente do que o de outros leites (Souza et al., 2005). No entanto, esse leite ainda é pouco utilizado como matéria-prima para a produção de iogurtes, sendo seu uso centrado na produção de queijos (Haenlein \& Wendorff, 2006).

O iogurte é um produto resultante da fermentação do leite, realizada por Lactobacillus bulgaricus e Streptococcus thermophilus (Brasil, 2007), processo em que o leite sofre modificações das suas propriedades sensoriais (Ordóñez, 2005). Contém todos os constituintes nutricionais do leite, com exceção da lactose, reduzida durante a fermentação, revelando-se vantajoso para quem não digere bem o leite. O iogurte é o fermentado mais popular e de maior importância econômica, além de ser uma excelente fonte de aminoácidos (Tamime \& Robinson, 1991).

Por essa razão, o objetivo deste trabalho foi obter e caracterizar (físico-química, reológica e microbiologicamente) iogurtes elaborados a partir de leite de ovelha (integral e semidesnatado) e de leite de vaca (integral e desnatado).

\section{MATERIAL E MÉTODOS}

\section{Matéria-prima}

O leite de ovelha, de animais da raça Lancaune, utilizado neste trabalho, foi adquirido da cabana Chapecó, do município de Chapecó, SC. O leite in natura (integral- sem padronização de gordura) foi pasteurizado, de forma lenta (63 $\left.{ }^{\circ} \mathrm{C} / 30 \mathrm{~min}\right)$, em tanque de aço inoxidável encamisado e, posteriormente, semidesnatado com desnatadeira (Elecrem $\left.{ }^{\circledR}\right)$. Para os ensaios, foram utilizados o leite integral e o semidesnatado.

Os leites de vaca integral e semidesnatado foram adquiridos em mercados da região de Erechim, RS, em embalagens de $1 \mathrm{~L}$. Em seguida, os leites de ovelha e vaca foram submetidos aos processos de elaboração de iogurtes, na Usina Piloto de Leites e derivados, da URI/ Campus Erechim.

\section{Elaboração de iogurte}

O processo de elaboração dos iogurtes à base de leite de ovelha e de vaca é apresentado no fluxograma da Figura 1.

A metodologia utilizada para a elaboração dos iogurtes de leite de ovelha e de vaca foi a descrita por Krolow \& Ribeiro (2006), adaptada. Primeiramente, $10 \mathrm{~L}$ de leite foram adicionados à iogurteira (Menoncin), homogeneizados e pré-aquecidos a $55^{\circ} \mathrm{C}$; em seguida, foi adicionado o açúcar $(11,5 \%)$ e, novamente, homogeneizado, por $1 \mathrm{~h}$, mantendo-se a temperatura de $55^{\circ} \mathrm{C}$. Posteriormente, o leite foi resfriado a $43{ }^{\circ} \mathrm{C}$ e foram adicionados $2 \%$ de cultura lática (Lactobacillus bulgaricus e Streptococcus termophillus).

Após o iogurte ter atingindo o $\mathrm{pH}$ desejável $(\mathrm{pH} 4,6)$ dentro da iogurteira, o gel foi resfriado até $35^{\circ} \mathrm{C}$ e quebrada a coalhada. Em seguida, foram adicionados sorbato de potássio $0,05 \%$ (Merck), aroma de cereja 0,16\% (Duas Rodas) e corante alimentício vermelho 0,08\% (Arcolor), homogeneizado e embalado em embalagens individuais, de $200 \mathrm{~mL}$, de poliestireno, previamente esterilizadas, seladas (com lacres de alumínio e identificadas) e resfriadas, a $4{ }^{\circ} \mathrm{C}$, em uma câmara fria por 30 dias. $\mathrm{O}$ aroma de cereja foi escolhido, por ser pouco usado como aroma em iogurtes e pelo fato de a empresa Duas Rodas tê-lo cedido para teste.

\section{Caracterização dos leites e iogurtes}

Dos leites de ovelha e de vaca, bem como dos iogurtes elaborados com leite de ovelha e de vaca, foram realizadas as análises (em triplicata) de $\mathrm{pH}$, acidez, proteínas, lactose, gordura, cinzas e minerais.

$\mathrm{O}$ pH foi determinado com o potenciômetro, segundo procedimento de (Silva et al., 1997). A acidez e o teor de proteínas foram determinados de acordo com o método AOAC (2000). O teor de lactose foi obtido conforme metodologia descrita pela norma FIL-IDF 28 A (1974). A gordura foi determinada por meio da metodologia descrita pela norma FIL-IDF 5B (1986). O conteúdo de cinzas foi obtido pela metodologia descrita por Foschiera (2004). A partir das cinzas obtidas, foram calculados os minerais (cálcio, sódio e potássio), os quais foram determinados por espectrometria de absorção atômica em chama - FAAS (VarianSpectra AA-55), segundo metodologia descrita por AOAC (1995).

\section{Análise reológica - Sinérese}

A análise reológica de sinérese foi realizada (em triplicata) nos iogurtes elaborados com leite de ovelha e de vaca, pelo método de drenagem, de acordo com Manzano (2007), calculada por meio da Equação 1:

Sinérese $(\%)=[($ peso do soro após filtração/peso da amostra) $\mathrm{x} 100]$ 


\section{Análises microbiológicas}

As análises microbiológicas foram realizadas (em triplicata) nos leites de ovelha e de vaca e nos iogurtes com eles elaborados, segundo recomendações e exigências da RDC n. 12 (Brasil, 2001), para Salmonella spp, Coliformes a $35^{\circ} \mathrm{C}$ e Staphylococcus coagulase positiva. Para a contagem, utilizou-se o Sistema de Placas de Petrifilm (3M), seguindo-se as recomendações do fabricante.

\section{Análise estatística}

As amostras foram submetidas à Análise de Variância (ANOVA) e ao Teste de Tukey a 95\% (p<0,05) de significância, utilizando-se o programa Statistica ${ }^{\circledR}$ 8.0.

\section{RESULTADOS E DISCUSSÕES}

\section{Análises dos leites de ovelha e de vaca}

Os resultados das análises físico-químicas dos leites de ovelha e de vaca são apresentados na Tabela 1.

Pode-se verificar que o leite de ovelha, tanto integral como semidesnatado, apresenta valores de $\mathrm{pH}$, acidez, gordura, proteína, cinzas e sódio maiores que os do leite de vaca integral e semidesnatado. Porém, o leite de ovelha semidesnatado apresenta valor de potássio menor que os dos leites de vaca integral e semidesnatado, diferindo estatisticamente entre si $(\mathrm{p}<0,05)$; os teores de cálcio e de lactose não apresentaram diferença significativa $(\mathrm{p}>0,05)$. Park et al. (2007) estudaram a composição dos leites de ovelha e de vaca e obtiveram teores de gordura iguais a 7,9 e 3,6\%, lactose 4,9 e $4,7 \%$, proteína 6,2 e $3,2 \%$ e cinzas 0,9 e $0,7 \%$, respectivamente.

Segundo Haenlein \& Wendorff (2006), quando o leite de ovelha é comparado ao leite de vaca, apresenta teores maiores de proteína. Brito et al. (2006) encontraram, em leites de ovelhas brasileiras da raça Lacaune, valores médios de proteína de $4,46 \%$, de lactose de $4,76 \%$ e de gordura de $5,79 \%$.
Souza et al. (2003) estudaram leite de vaca cru e pasteurizado e observaram valor de proteína igual a 3,0\%, semelhante ao encontrado, neste estudo, para o leite de vaca integral. Essas diferenças em relação ao teor de proteína dos leites podem estar associadas ao estádio da lactação, idade, número de cordeiros em aleitamento, nível nutricional durante a gestação e lactação, ambiente, técnicas de ordenha, estado sanitário e infecções de úbere (Bencini, 2001).

A gordura é um dos componentes mais importantes do leite de ovelha, pois tem função nutricional e influencia as características físicas e organolépticas. Está presente no leite em forma de glóbulos e sua quantidade varia muito, dependendo da raça, da alimentação, do período de lactação, etc (Gutiérrez, 1991).

O maior valor de $\mathrm{pH}(6,7)$ foi observado para o leite integral de ovelha, diferindo estatisticamente do $\mathrm{pH}$ dos demais leites analisados. Em relação à acidez, os leites de mesma origem, integral e semidesnatado, não diferiram entre si ( $p>0,05)$. Segundo Gutiérrez (1991) e Park et al. (2007), o valor médio do $\mathrm{pH}$ do leite de ovelha integral é 6,8-6,5 e a acidez titulável do leite de ovelha está compreendida na faixa normal entre 16 e 28 graus Dornic. A acidez é normalmente utilizada como indicador do estado de conservação do leite, em função da relação entre disponibilidade de lactose e produção de ácido láctico, por ação microbiana, que acarreta aumento da acidez e diminuição do teor de lactose (Park et al., 2007).

Os teores de lactose do leite de ovelha (integral, $4,9 \%$; e semidesnatado, $4,5 \%$ ) não diferiram estatisticamente ( $\mathrm{p}$ $<0,05$ ) dos teores do leite de vaca (integral, 4,6\% e desnatado, 4,5\%). Jandal (1996) afirma que os teores de lactose, tanto do leite de ovelha quanto dos de vaca são aproximadamente os mesmos.

Segundo Park et al., (2007), o leite de ovelha contém em torno $60 \%$ a mais de minerais que o de vaca. Outros minerais também são encontrados em maior quantidade
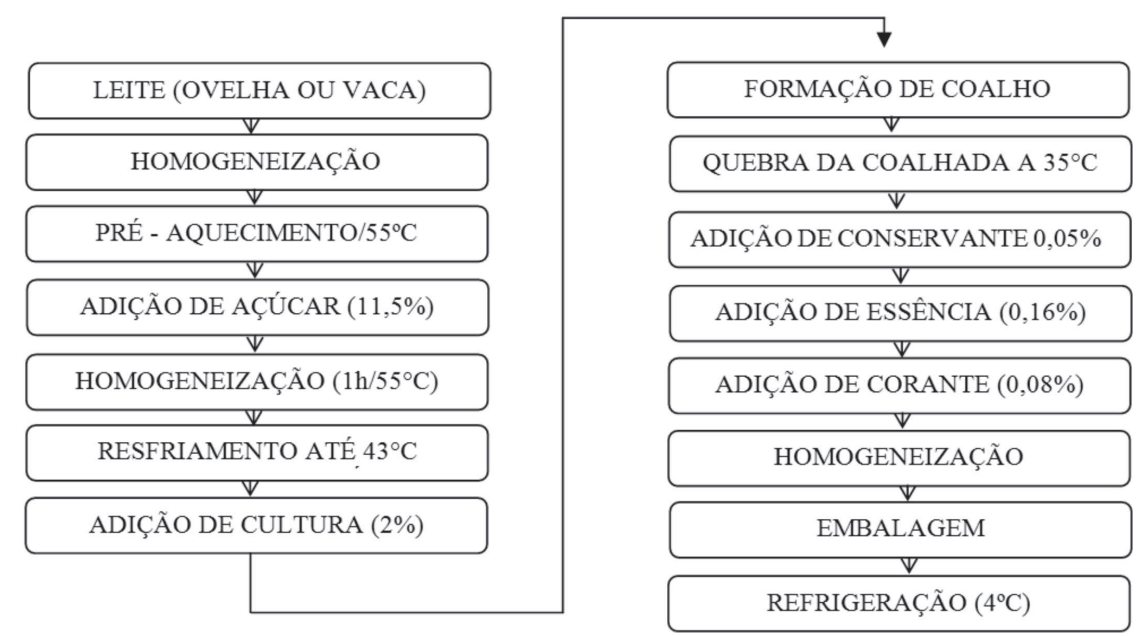

Figura 1: Fluxograma do processamento dos iogurtes elaborados com leite de ovelha e com leite de vaca. 
no leite de ovelha, como o cálcio e o potássio. O mesmo foi observado em nosso estudo (Tabela 1), que observou conteúdo de cinzas de $0,85 \%$, para o leite de ovelha integral; $0,75 \%$, para o leite de ovelha semidesnatado; $0,45 \%$, para o leite de vaca integral e $0,41 \%$, para o leite de vaca semidesnatado.

\section{Análises dos iogurtes elaborados com leite de ovelha e de vaca}

As análises físico-químicas e reológicas dos iogurtes elaborados com leites de ovelha e de vaca foram realizadas nos $1^{\circ}, 15^{\circ} \mathrm{e} 30^{\circ}$ dias de armazenamento, conforme resultados apresentados na Tabela 2 .

Verificou-se que o teor de gordura não diferiu estatisticamente $(\mathrm{p}<0,05)$, durante o armazenamento, para todos os iogurtes analisados, apresentando valores de aproximadamente 7,6 e $3,8 \%$, para os iogurtes de leite de ovelha integral e semidesnatado, e de 3,9 e 1,5\% para os iogurtes com o leite de vaca integral e semidesnatado, respectivamente. A legislação brasileira não estabelece valores de gordura para iogurtes de leite de ovelha, somente para iogurtes à base de leite de vaca, para o que estabelece valores de 3,0 a 5,9\%, para iogurtes integrais, e de 0,6 a $2,9 \%$, para os semidesnatados (Brasil, 2000). Portanto, os iogurtes elaborados com leite de vaca, neste trabalho, estão dentro dos padrões exigidos pela legislação. Segundo Thomopoulos et al. (1993), o teor de gordura do leite altera favoravelmente a qualidade do iogurte, a gordura estabiliza a contração do gel proteico, previne a separação do soro no produto final e afeta a percepção sensorial do produto, que apresenta textura mais macia e cremosa.

Os teores de proteína também não diferiram estatisticamente entre si $(\mathrm{p}<0,05)$ durante o armazenamento, para os quatro tipos de iogurtes. Segundo Danone (2004), o valor nutricional das proteínas do leite é praticamente inalterado durante a fermentação, podendo o iogurte ser considerado um "leite pré-digerido", pois a atividade proteolítica das culturas lácticas do iogurte resulta em uma alta concentração de peptídeos e aminoácidos li- vres. Os resultados obtidos para o teor de proteína de todos os iogurtes estudados ficaram acima de 3\%, ou seja, dentro dos valores estabelecidos pela legislação brasileira em vigor (Brasil, 2000), que estabelece o mínimo de 2,9\% de proteínas lácteas. Segundo Rasic \& Kurmann (1978), leites fermentados com maior teor de proteínas apresentam um maior tempo de vida útil. Rodas et al. (2001) caracterizaram iogurtes de frutas de diferentes marcas comerciais e observaram valores de proteína entre 2,51 e $3,40 \%$, resultados abaixo dos encontrados neste estudo.

De acordo com os resultados apresentados na Tabela 2 para o $\mathrm{pH}$, pode-se observar que houve uma ligeira diminuição dos valores ao longo dos 30 dias de armazenamento para todos os iogurtes (com leite de ovelha, integral e semidesnatado; leite de vaca, integral e semidesnatado). Este mesmo comportamento foi observado por Martin (2002), Oliveira \& Damin (2003) e Preci et al. (2011), que avaliaram o tempo de estocagem de iogurtes. Beal et al. (1999) afirmam que os iogurtes estão sujeitos ao decréscimo de $\mathrm{pH}$, por causa da produção continuada de ácidos, pelas bactérias lácticas, durante a estocagem do produto.

No primeiro dia de armazenamento dos iogurtes, o teor de lactose apresentou os maiores valores, diferindo estatisticamente dos teores dos demais dias de armazenamento ( $\mathrm{p}<0,05)$. O mesmo comportamento foi observado por Mundin (2008), que estudou iogurte funcional com leite de cabra. Segundo Tamime \& Robinson (1991), a lactose é fonte de energia para os micro-organismos do iogurte, sendo desta forma consumida durante o processo de fermentação. Os valores apresentados de consumo de lactose estão de acordo com os de Galvão et al. (1995), que relataram um consumo entre 10 e $30 \%$ de lactose durante a fermentação e armazenamento dos iogurtes.

De acordo com os resultados da Tabela 2, observou-se incremento dos teores dos de $\mathrm{Na}$, $\mathrm{Ca}$ e $\mathrm{K}$, com o passar dos dias de armazenamento, para todos os iogurtes estudados. Segundo Novello \& Preis (2012), esse aumento pode ser devido à perda de água pela sinérese. Os valores da

Tabela 1: Resultado das análises físico-químicas do leite de ovelha e do leite de vaca

\begin{tabular}{|c|c|c|c|c|}
\hline Análises & $\begin{array}{c}\text { Leite de ovelha } \\
\text { integral }\end{array}$ & $\begin{array}{l}\text { Leite de ovelha } \\
\text { semidesnatado }\end{array}$ & $\begin{array}{c}\text { Leite de vaca } \\
\text { integral }\end{array}$ & $\begin{array}{c}\text { Leite de vaca } \\
\text { semidesnatado }\end{array}$ \\
\hline $\mathrm{pH}$ & $6,7( \pm 0,04)^{\mathrm{a}}$ & $6,5( \pm 0,01)^{b}$ & $6,3( \pm 0,02)^{\mathrm{d}}$ & $6,4( \pm 0,03)^{\mathrm{c}}$ \\
\hline Acidez (\% ác.lático) & $0,3( \pm 0,01)^{\mathrm{a}}$ & $0,3( \pm 0,01)^{\mathrm{a}}$ & $0,2( \pm 0,02)^{\mathrm{b}}$ & $0,2( \pm 0,01)^{\mathrm{b}}$ \\
\hline Gordura $(\%)$ & $9,0( \pm 0,04)^{\mathrm{a}}$ & $4,5( \pm 0,02)^{b}$ & $3,0( \pm 0,02)^{\mathrm{c}}$ & $1,5( \pm 0,02)^{\mathrm{d}}$ \\
\hline Proteínas $(\%)$ & $5,8( \pm 0,04)^{\mathrm{a}}$ & $5,3( \pm 0,02)^{b}$ & $2,9( \pm 0,01)^{\mathrm{c}}$ & $0,8( \pm 0,01)^{\mathrm{d}}$ \\
\hline Cinzas $(\%)$ & $0,8( \pm 0,01)^{\mathrm{a}}$ & $0,7( \pm 0,01)^{\mathrm{b}}$ & $0,5( \pm 0,04)^{\mathrm{c}}$ & $0,4( \pm 0,01)^{\mathrm{c}}$ \\
\hline $\mathrm{Na}(\mathrm{mg} / \mathrm{kg})$ & $141,6( \pm 2,47)^{\mathrm{b}}$ & $175,2( \pm 3,87)^{\mathrm{a}}$ & $80,0( \pm 1,32)^{\mathrm{c}}$ & $79,0( \pm 1,67)^{\mathrm{c}}$ \\
\hline $\mathrm{Ca}(\mathrm{mg} / \mathrm{kg})$ & $255,0( \pm 3,00)^{\mathrm{a}}$ & $218,7( \pm 2,00)^{\mathrm{b}}$ & $220,0( \pm 1,54)^{\mathrm{b}}$ & $219,0( \pm 3,00)^{\mathrm{b}}$ \\
\hline $\mathrm{K}(\mathrm{mg} / \mathrm{kg})$ & $61,2( \pm 2,04)^{\mathrm{a}}$ & $33,2( \pm 0,04)^{\mathrm{c}}$ & $59,0( \pm 1,40)^{\mathrm{a}}$ & $48,7( \pm 0,04)^{b}$ \\
\hline Lactose $(\%)$ & $4,9( \pm 1,04)^{\mathrm{a}}$ & $4,5( \pm 0,50)^{\mathrm{a}}$ & $4,6( \pm 0,54)^{\mathrm{a}}$ & $4,5( \pm 0,94)^{\mathrm{a}}$ \\
\hline
\end{tabular}

*letras minúsculas iguais nas linhas indicam não haver diferença significativa entre si $(\mathrm{p}<0,05)$. 


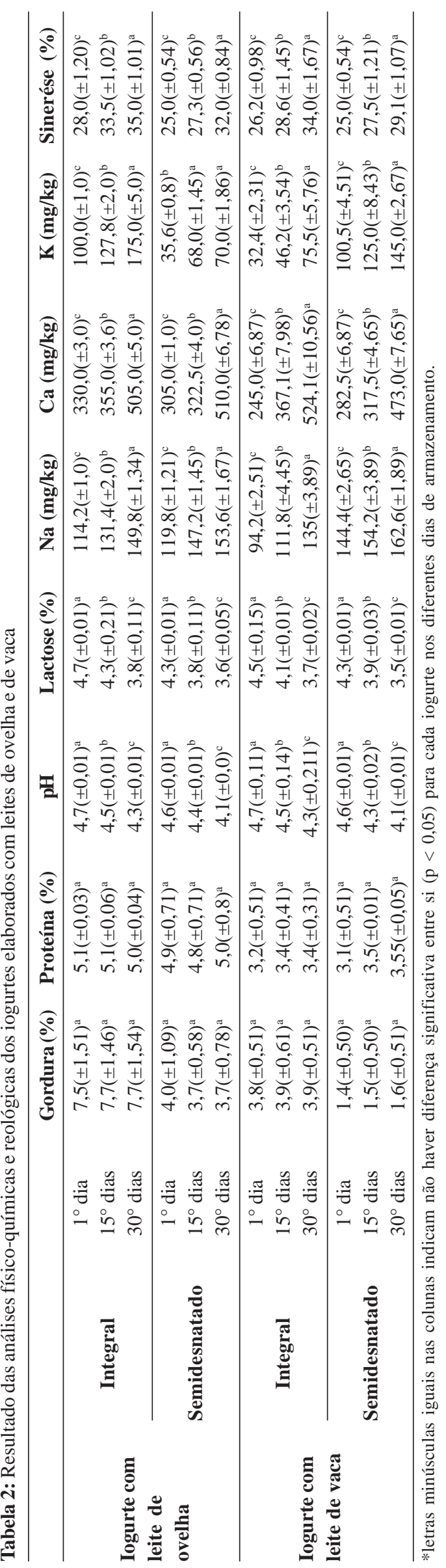

sinérese também apresentaram aumento com o passar dos dias de armazenamento (Tabela 2), atingindo o máximo de $35 \%$, para o iogurte de leite de ovelha integral no $30^{\circ}$ dia. Esse mesmo comportamento foi observado por Toledo (2013), ao estudar a elaboração de iogurtes de maracujá. Segundo Ramirez-Santiago et al., (2010), isto pode ocorrer por causa dos graves rearranjos na rede da caseína, que promovem a expulsão do soro. Pimentel (2009) sugere que o aumento da sinérese é devido ao decréscimo do $\mathrm{pH}$ durante a estocagem, o que provoca contração da matriz micelar de caseína, aumentando então a liberação do soro, e que valores de sinérese abaixo de $39 \%$ podem ser considerados satisfatórios.

A composição físico-química dos iogurtes (Tabela 2) é similar à dos leites (Tabela 1), embora haja algumas diferenças, por mudanças ocorridas pela fermentação bacteriana sobre a lactose e pela adição de aditivos e flavorizantes, comportamento observado por Martin (2002), que estudou o armazenamento do iogurte comercial e seu efeito na proporção das bactérias láticas.

\section{Análises microbiológicas dos leites e dos iogurtes}

Os resultados verificados nos leites de ovelha (integral e semidesnatado) e de vaca (integral e semidesnatado), usados para a elaboração dos iogurtes, indicaram ausência de Salmonella spp., Coliformes $35^{\circ}$ e Staphylococcus coagulase positiva, para $25 \mathrm{~g}$ de amostra. Portanto, de acordo com a resolução $n^{\circ} 12$, de 2 de janeiro de 2001, ambos os leites utilizados para a elaboração dos iogurtes estão dentro dos padrões determinados pela Resolução RDC, de 12 de janeiro de 2001, da Agência Nacional de Vigilância Sanitária (Brasil, 2001).

\section{CONCLUSÕES}

Conforme as análises realizadas para as amostras dos leites de ovelha e de vaca, notaram-se diferenças significativas e marcantes, com relação a praticamente todos os parâmetros analisados, demonstrando a individualidade de cada tipo de leite. Observou-se que leite ovino apresentou valores para características físicoquímicas, em quase todos os parâmetros maiores que os do leite bovino, sendo que o mesmo comportamento foi observado para os iogurtes. As análises microbiológicas realizadas para os diferentes leites e iogurtes estiveram dentro dos padrões exigidos pela legislação vigente, refletindo, assim, a qualidade higiênica da ordenha e do processamento.

Os resultados obtidos neste trabalho evidenciam a maior riqueza nutricional que o leite de ovelha apresenta em relação ao leite de vaca, mostrando o potencial de aplicação deste leite na fabricação de iogurtes. 


\section{AGRADECIMENTOS}

Os autores agradecem à FAPERGS, ao CNPq, à CAPES e à URI, pelo apoio financeiro.

\section{REFERÊNCIAS}

AOAC - Association of Official Analytical Chemists (1995) Official methods of analysis. $16^{\text {th }}$ ed. Arlington, AOAC international. $1141 \mathrm{p}$.

AOAC - Association of Official Analytical Chemists (2000) Official methods of analysis. $17^{\text {th }}$ ed. Gaithersburg, AOAC. 1170p.

Barbosa AS, Araujo AS, Martins WF, Araújo MSR \& Florentino ER (2010) Utilização do soro como substrato para produção de aguardente: estudo cinético da produção de etanol. Revista Verde de Agroecologia e Desenvolvimento Sustentável, 5:63-79.

Beal C, Skokanova J, Latrille E, Martin N \& Corrieu G (1999) Combined effects of culture conditions and storage time on acidi P cation and viscosity of stirred yogurt. Journal of Dairy Science, 82:673-681.

Bencini R (2001) Factors affecting the quality of ewe's milk. Disponível em: <http://www.uwex.edu/ces/animalscience/sheep/ Publications_and_Proceedings/res.html>. Acessado em: $27 \mathrm{de}$ janeiro de 2014.

Brasil (2000) Ministério da Agricultura. Secretaria Nacional de Defesa Agropecuária. Departamento de Inspeção de Produtos de Origem Animal. Resolução $n^{\circ}$ 5. Padrões de identidade e qualidade de leites fermentados. DOU, 13/11/ 2000, Seção 1, p.9.

Brasil (2001) Ministério da Saúde. Agência Nacional de Vigilância Sanitária. Resolução RDC no 12 de 02 de janeiro de 2001. Dispõe sobre o regulamento técnico sobre padrões microbiológicos para alimentos. DOU, 02/01/2001, Seção 1, p.174.

Brasil (2007) Ministério da Agricultura Pecuária e Abastecimento - MAPA. Instrução Normativa ${ }^{\circ}$ 46, de 23 de outubro de 2007 , que adota o Regulamento Técnico de Identidade e Qualidade de Leites Fermentados. DOU, 24/10/2007, Seção 1, p.5.

Brito MA, González FD, Ribeiro LA, Campos R, Lacerda L, Barbosa PR \& Bergmann G (2006) Composição do sangue e do leite em ovinos leiteiros do sul do Brasil: variações na gestação e na lactação. Ciência Rural, 36:942-948.

Danone (2004) Processo de fabricação de iogurte. Disponível em: <http://www.danone.com.br/estudantes.php>. Acessado em: 08 de Novembro de 2014.

FIL-IDF - International Dairy Federation (1974) Determination of lactose content of milk. Brussels, Robinson RK. 43p.

FIL-IDF - International Dairy Federation (1986) Cheese and processed cheese products. Determination of fat content gravimetric method 5B. Brussels, Robinson RK. 7p.

Foschiera JL (2004) Indústria de laticínios: industrialização do leite, análises, produção de derivados. Porto Alegre, Suliani Editografia Ltda. 88p.

Galvão LC, Fernandes MI \& Sawamura R (1995) Absorção de lactose e tolerância a diferentes tipos de iogurtes em adultos com hipolactasia. Arquivos de Gastroenterologia, 33:10-16.

Gutiérrez RB (1991) Elaboración artesanal de quesos de ovejas. Montevideo, MGAP / JUNAGRA / UAPAG. 130p.

Haenlein GFW \& Wendorff WL (2006) Sheep milk: production and utilization. In: Park YW \& Haenlein GFW (Eds.) Handbook of Milk of Non-bovine Mammals. Ames, Blackwell Publishing. p.137-194.
Jandal JM (1996) Comparative aspects of goat and sheep milk. Small Ruminant Research, 22:177-185.

Krolow ACR \& Ribeiro MER (2006) Obtenção de leite com qualidade e elaboração de derivados. Pelotas, Embrapa Clima Temperado. 64p. (Documentos 154)

Manzano GPP (2007) Aspectos sensoriais e físico-químicos de "iogurtes" de soja com espessantes/estabilizantes à base de fécula de inhame (Dioscoreaalata), amido modificado e gelatina. Dissertação de Mestrado. Universidade Estadual Paulista "Júlio Mesquita Filho", Araraquara. 76p.

Martin AF (2002) Armazenamento do iogurte comercial e o efeito na proporção das bactérias lácticas. Dissertação de Mestrado. Universidade de São Paulo, Piracicaba. 62p.

Mundin SAP (2008) Elaboração de iogurte funcional com leite de cabra, saborizado com frutos do cerrado e suplementado com inulina. Dissertação de Mestrado. Universidade Federal do Rio de Janeiro, Rio de Janeiro. 133p.

Novello Z \& Preis C (2012) Desenvolvimento e caracterização de queijo minas curado elaborado com leite de ovelha. Disponível em: <http:// www.farmpoint.com.br/cadeia-produtiva/dicasdesucesso/ desenvolvimento-e-caracterizacao-de-queijo minascurado-elaborado-com-leite-de-ovelha-78637n. aspx $>$ Acessado em: 07 de agosto de 2014.

Oliveira MN \& Damin MR (2003) Efeito do teor de sólidos e da concentração de sacarose na acidificação, firmeza e viabilidade de bactérias do iogurte e probióticas em leite fermentado. Ciência e Tecnologia de Alimentos, 23:172-176.

Ordóñez PJA (2005) Tecnologia de Alimentos. Porto Alegre, Editora Artmed. 279p.

Park YW, Juárez M, Ramos M \& Haenlein GFW (2007) Physicochemical characteristics of goat and sheep milk. Small Ruminant Research, 68:88-113.

Pimentel TC (2009) Iogurte probiótico com inulina como substituto de gordura. Dissertação de Mestrado. Universidade Estadual de Londrina, Londrina. 154p.

Preci D, Cichoski AJ, Valduga AT, Oliveira D, Valduga E, Treichel H, Toniazzo G \& Cansian RL (2011) Desenvolvimento de iogurte light com extrato de erva-mate (Ilex paraguariensis St. Hil) e adição de probióticos. Alimentos e Nutrição, 22:27-38.

Rasic J \& Kurmann JA (1978) Yoghurt: Scientific Grounds, Technology, Manufacture and Preparactions. Copenhagen, Technical Dairy Publishing House. 466p.

Ramirez-Santiago C, Ramos-Solis L, Lobato-Calleros C, PeñaValdivia C, Vernon-Carter EJ \& Alvarez-Ramírez J (2010) Enrichment of stirred yogurt with soluble dietary fiber from Pachyrhizus erosus L. Urban: Effect on syneresis, microstructure and rheological properties. Journal of Food Engineering, 101:229-235.

Rodas MAB, Rodrigues RMMS, Sakuma H, Tavares LZ, Sgarbi CR \& Lopes WCC (2001) Caracterização físico-química, histológica e viabilidade de bactérias lácticas em iogurtes com frutas. Ciência e Tecnologia de Alimentos, 21:304-309.

Santos BM (2011) Elaboração e caracterização de queijo de leite de cabra "tipo coalho" com inclusão de leite de vaca. Dissertação de Mestrado. Universidade Federal da Paraíba, João Pessoa. 109p.

Silva PHF, Pereira DBC, Oliveira LL \& Costa Junior LCG (1997) Físico-química do leite e derivados - métodos analíticos. Juiz de Fora, Oficina de Impressão Gráfica e Editora Ltda. 190p.

Souza ACKO, Osorio M, Osório J, Oliveira N, Souza M \& Correa G (2005) Produção, composição química e características físicas do leite de ovinos da raça Corriedale. Revista Brasileira de Agrociência, 11:73-77.

Rev. Ceres, Viçosa, v. 63, n.6, p. 747-753, nov/dez, 2016 
Souza LG, Santos GT, Damasceno JC, Matsushita M, Sakaguti ES, Ribas NP \&Villalba RG (2003) Avaliação da composição e do perfil de ácidos graxos do leite de vaca cru e pasteurizado em minilaticínios. Acta Scientiarum - Animal Sciences, 25:331337.

Tamime AY \& Robinson RK (1991) Yogur: Ciencia y Tecnologia. Zaragoza, Acribia. 368p.
Thomopoulos C, Tzia C \& Milkas D (1993) Influence of processing of solidsfortified milk on coagulation time and quality properties of yogurt. Milchwissenschaft, 48:426-430.

Toledo NMV (2013) Aproveitamento de subprodutos da industrialização do maracujá para elaboração de iogurte. Dissertação de Mestrado. Universidade de São Paulo, Piracicaba. 129p. 